\title{
An extra-curricular gifted support program in Hungary for exceptional students in mathematics
}

\section{János GORDON GYŐRI, Péter JUHÁSZ}

Research conducted on nurturing talent and thus the literature on the subject are predominantly about the gifted people themselves, and those educational programmes that support them in optimising their abilities during the stages of their development. Thanks to relatively popular research projects a number of lists of varying accuracy are available of the cognitive, professional and personality traits as well as other important characteristics of qualified teachers working with gifted children in gifted development programmes, while significantly less is known about those people who, despite not having formal pedagogical qualifications and not receiving regular training in this area, are able to nurture the development of gifted individuals (often generations of them) with outstanding success. Examples include sports coaches, arts teachers who run extracurricular activities for their students in the areas of music, dance, painting or other branches of art, professionals working in a range of non-profit and for-profit organisations, and many others. These people are the same in certain respects: they all work with a high degree of efficiency (many of them produce great results for decades or throughout their whole careers); entire schools of methodology are built around many of them; and they are surrounded by educators dealing with gifted children who want to learn from them, continue and further develop their methods. However, they each differ in regard to whether they themselves were ever active in the given area - i.e. whether they were outstanding sportsmen, artists or scientists at any period of their lives - or they have the ability to achieve something extraordinary and lasting in the development of those gifted in a given area without being outstandingly talented themselves in the same area. 
There are numerous examples for the above from all over the world, both from the past and the present, also in the area of nurturing those gifted in the natural sciences. Hence, it seems peculiar how little attention has been focused on this field by research, especially since valuable findings could be gained from answering the question of why these people who themselves do not possess regularly and formally structured pedagogical knowledge, including pedagogical knowledge relating to the education of talented children, are capable of developing efficient pedagogical practices in their own careers, i.e. practices that, if successfully applied, could determine the development of individual areas of gifted education pedagogy for decades. It certainly does not suffice to simply say that these people use 'layman's pedagogy' as it is well known that besides the layman's theories pertaining to other areas of life (Furnham, 1988), everyone possesses layman's pedagogy; however, these talented gifted educators not only exploit their 'layman's pedagogy' but also have special pedagogical understanding and practices in the given areas enabling them to produce results that on occasion are significantly more efficient and successful than those achieved by professional gifted educators who have formal qualifications and receive formal training in their area of expertise. Despite the extensive research into the theme of gifted development, surprisingly little attention has been devoted by researchers to how the afore-mentioned, specially efficient pedagogies are constructed and continuously shaped in the case of pedagogically untrained educators.

A key role in understanding this phenomenon is certainly to be attributed to situated learning (Lave \& Wenger, 1991), i.e. learning through experience, since these successful gifted educators obviously (also) have an outstanding talent for selecting and integrating into their cognitive systems those elements from the complex and in many ways chaotic system of situations and experiences in which they work that lead them to the discovery of productive pedagogical practices and their practical implementation.

Of course Hungary has its own special gifted educators in the natural sciences. Such a person in today's gifted education for students of mathematics is Lajos Pósa. Those who regard themselves as knowledgeable about gifted education in today's Hungary for students of mathematics are well aware of the following: if a researcher in this area maps out the institutional, structural and contentual elements of Hungarian gifted education in mathematics with the accuracy of a philologist, exploring every relevant aspect of it, but is not familiar with 
Lajos Pósa's exceptionally successful activity of many decades in Hungarian gifted education in mathematics, he or she knows little and can only understand little about the current situation and efficiency of this area in Hungary.

Lajos Pósa belongs to the group of outstanding gifted educators without formal pedagogical/gifted pedagogical qualifications whose members themselves are preeminent representatives of the given area in which they nurture talent: Pósa is an excellent mathematician, with a scientific activity having elevated him into the top of the profession internationally. He is a scientist whose systematic work pursued over decades has led to the creation of an extraordinary school of gifted pedagogy in mathematics in Hungary. His students now carry on and try to further develop his method in the area of gifted pedagogy in mathematics (the second author of this study is one such former student). Using the methodology of biographical case study research (Zucker, 2009), our chapter will discuss Pósa's person and the activity he carried out in gifted pedagogy in the natural sciences; this close-up will introduce some of the elements that illustrate how an area of gifted education actually came into being in the course of the professional development of a pedagogically untrained individual, who is a defining figure of the area. Some light will also be shed in the chapter on how the system of professional knowledge and activity thus constructed has been passed down to the 'talent-raising students' of Pósa, the founder of the original school, who carry on the legacy, thus creating continuity within the given area of gifted education and ensuring long-term efficiency and the potential for development in the area, which are of fundamental importance in gifted pedagogy.

\section{Family and school background}

Lajos Pósa's entire life was interwoven with the science of mathematics and by teaching mathematics, the latter being pursued both as the pedagogy of a subject and as an area of gifted development pedagogy. He was born in 1947 into a middle class family of intellectuals living in Budapest. His father was a chemist, while his mother worked as a teacher of mathematics, first in primary and secondary education, then at the Teacher Training College in Budapest, and finally at the prestigious Loránd Eötvös University of Arts and Sciences. She even wrote a textbook on teaching mathematics. She died at a young age in 1960, when Pósa was only 13 years old, on the borderline between childhood and adolescence. Various research projects, as well as biographies 
of artists and scientists (Czeizel \& Batta, 1992) confirm that children's development is extremely sensitive at this age, and traumatic loss, such as losing a parent, suffered at this time can cause a trauma for life, while it can also lead to a life-long high performance motivation, provided, of course, that a number of other factors is also present.

The maternal model had an obviously inspirational role in Lajos Pósa's professional development and thus in his work in gifted pedagogy. School and education were regarded by his family as one of the fundamental values in life, and, within that, so were the practice of teaching mathematics and the methodology related to it. All this was realised in the course of his mother's development - partly as a result of her own choice and partly as a result of events outside her control - in the form of a continuously rising professional career that started with teaching in an elementary school and ended with being a lecturer at the professionally most prestigious university of the country. This probably not only confirmed in Pósa's mind that huge professional change and development can take place within a relatively short span of time both in the actual pedagogical activity of teaching a subject, its meta-level interpretations[,] and in mediating the acquired systems of knowledge to the next generations but also showed him the importance and value of mathematical pedagogy. His mother's model might have also exerted a significant influence on Pósa in the sense that for him mathematics as a discipline and mathematical pedagogy were never opposite parts of a dichotomy excluding each other; on the contrary, as will soon be discussed, pursuing mathematical studies and teaching mathematics (especially working with outstandingly talented individuals) were seen by him from early adulthood as elements that can be integrated successfully - ones that, as proven by his own activity, can mutually support each other in a synergy.

Before exploring this aspect any further, it is important to mention something in Lajos Pósa's education that was of great importance in regard to gifted pedagogy: namely his secondary school studies and some of its specific elements. In 1962, i.e. two years after his mother's death, Pósa was granted admission to the special math class in the Mihály Fazekas Secondary School in Budapest (later called Mihály Fazekas Primary and Secondary Grammar School of Budapest) in a pull-out gifted education class for mathematically exceptional pupils. Special importance is lent to this by the fact that it was the first such class in Hungary during the socialist era, and if mathematics is included in the natural sciences, then it was the country's first gifted education 
class in the natural sciences (Stockton, 2010) in the period. The mere existence of a class where gifted education is carried out in a single subject was previously impossible in socialist Hungary, which upheld the principle of overall sameness and equality with everything that could be seen as elitist being rejected by its educational policy, even if it only applied to knowledge and not social class. The establishment of special math classes was basically made possible by the changes that took place in the Soviet Union at the time. After Khrushchev rose to power a number of gifted education schools were established in the Soviet Union in the area of the natural sciences (Borovik,2012; Szegal, 1989; Vogeli, 1968), among them several outstanding schools with classes specialising in mathematics (for example, Kolmogorov's schools). A smaller scale version of this was later realised at the level of classes with mathematical specialisation, called 'spec. math.' (Fried, 2010). The methodology only worked for mathematical specialisation since all other attempts made at establishing similar specialised classes in other natural science subjects in Hungary ended either without any or at most short-lived success. (They were successful only in slightly modified forms). The high level that distinguished these classes specialised in mathematics is beautifully illustrated by the fact that according to Kolmogorov teaching in the Hungarian spec. math. classes was characterised by a higher level of abstraction than in the Soviet gifted education schools - in fact, he claimed that it was done at too abstract a level (Fried, 2010).

The class for teaching pupils gifted in mathematics in Fazekas was organised in a rather hasty fashion, the reasons for which can no longer be accurately researched but it can be assumed that most probably neither the Hungarian academic elite, nor the involved educational professionals and those teachers they invited to participate in the project would have liked a unique opportunity like this one to be lost because of another political/ideological change of direction. The members of the specialised class were selected by the maths teacher Imre Rábai, who was requested to do so by a department of the ministry of education; the time pressure to launch the class meant that in some cases it might have been merely a matter of luck if someone got admitted into this class (Szabó \& Orosz, 2012).

This first special math class was perhaps organised too fast, but it nevertheless added an outstanding success story to the history of Hungarian pedagogy since all the members of the International Mathematical Olympiad of 1966 were from this class, and five of them - including 
Pósa himself - won gold medals. Other members of this class included László Lovász, the holder of the Wolf, Kyoto, and more than a dozen other awards, and currently the president of the Hungarian Academy of Sciences; József Pelikán, who has been the head of the Hungarian teams participating in the mathematical Olympiads for decades with outstanding international success; as well as KatalinVesztergombi, István Berkes, Miklós Laczkovich, Péter Major and others who later became excellent mathematicians of Hungary and all of whom are internationally well known and highly recognised professionals.

Although Pósa had written scientific publications of great importance even before being selected for the specialised math class of Fazekas Secondary School (he co-authored seven studies with Pál Erdős after his mother's death in 1960, i.e. from the age of 13), it is certain that the years in Fazekas exerted a significant influence on his development. Above all, it was his form-master, Gyula Komlós, a teacher of history and geography, who served as a source of major inspiration for him; Pósa said nothing less of him than this: "What I think about this world is, to the most part, his thoughts". (Pósa, 2013).

No sooner had Pósa begun his studies at Loránd Eötvös University of Arts and Sciences after graduating from secondary school, than his interest turned to the teaching of mathematically talented pupils: as a freshman he went back to his former secondary school, where he organised an extracurricular program, i.e. he was the gifted educator for children who later had outstanding careers as mathematicians, such as László Babai, György Elekes and László Surányi. It was a great achievement and a later result of his successful work that Pósa organised numerous mathematical workshops in schools in the decades that followed for those gifted in mathematics that were often held not by him personally but by his students.

It was in the early 1970s, directly after Pósa graduated from university, that he became affiliated with the new mathematical education in Hungary, i.e. with the internationally renowned complex teaching of mathematics developed by Tamás Varga and János Surányi (Huszár, 2011). One of the reasons why this method attracted Pósa's interest was its children and thinkingcenteredness, placing great emphasis on the pupils' independent work, the development of their problem-solving skills, and teaching mathematics through discovery, i.e. principles Pósa himself had already shared during his university years, then put into practice as a university lecturer 
between 1971 and 1982, and later passed on to future mathematicians and teachers of mathematics as an approach to embrace.

In these and the following years Lajos Pósa worked with numerous gifted children both individually and in groups, while also participating in many summer camps organised for nurturing mathematical talent. The latter inspired him to organise and hold similar camps for gifted children himself, although his approach was different than what he saw in other camps.

In the following section Lajos Pósa's basic principles of teaching mathematics will be discussed, followed by the theory and practice of weekend math camps as one the forms of gifted education he pursued and perhaps regarded as the most important.

\section{Basic principles of teaching mathematics ${ }^{1}$}

Lajos Pósa's teaching principles are based on the contention that thinking is enjoyed by all but thoroughly and systematically developed conditions must be created for it, which is the challenging task of the teacher, who needs to have extensive knowledge and consideration for many things, and, as far as possible, familiarity with children of the given group and the knowledge they previously acquired.

The most important principle, therefore, is that children must be given time to think about the solutions for mathematical problems, which is the opposite of the usual practice of the teacher explaining a method or a theorem to the pupils, or building up a complete mathematical area, after which the pupils are given exercises to practise. Unfortunately, both in Hungary and in many other countries of the world it is the most widely used method in teaching mathematics. However, in such an approach the pupils are excluded from the creative work, which is crucially important, and they are deprived of the opportunity to think independently.

The traditional method of teaching mathematics is undoubtedly based on the communication of important information by teachers, and, primarily, passive reception of this information by the pupils. Hence, no opportunity is provided to develop independent, creative thinking, and to master the technique of asking questions. The traditional method teaches pupils that there is a 'good' answer for every question, which is often the only possible answer or

\footnotetext{
${ }^{1}$ The next parts are partially based on personal interviews with Lajos Pósa
} 
solution method, and, moreover, the questions are always asked by the teacher, i.e. they come from without. In dire contrast to this approach is teaching through discovery, which is a gradual process in which new things slowly come into being. After Rózsa Péter and Tibor Gallai, one of the most impactful representatives of this way of teaching was Tamás Varga, and currently it is Lajos Pósa (Fried, 2010). Teaching through discovery resembles far more the situation customary in front-line research, where the researcher asks the questions, and does not know whether he or she will or will not be able to find the answer. The researcher must decide if the conclusion arrived at is the correct one, and there are no external forces that will decide if he or she used the right method to solve the given problem.

A frequently used practice in many mathematics lessons is that after proposing a problem (which is rather called an exercise or practice task) the teacher provides the solution, or in a slightly better scenario, he or she waits for the first few pupils who complete the task, and then the solution is provided. For most pupils the most important part of the knowledge that can be acquired in a mathematics lessons should be to learn how to think independently, inquisitively and creatively in situations that are unfamiliar to them. When they become adults, most pupils will not need the factual knowledge taught in mathematics; however, they will not possess the important skill of creative problem solving either if all they do in most cases is listen to the solution given by the teacher or faster pupils without being given the chance to make at least some progress on the path that could lead to a solution.

During mathematics lessons there is one open problem (task, exercise) at a time in the majority of cases. Every pupil is asked to think about that single problem and those who have succeeded have nothing else to think about. In contrast, during the workshops led by Pósa and his students there is almost always more than one problem awaiting a solution - usually three or four, or even more than that - which enables pupils to choose the task they prefer, making it more enjoyable since it is up to him or her when to work on which problem, and it is also a more efficient approach to solving the problem of active involvement as not a single pupil will be bored in the lesson if the tasks are selected thoughtfully. During the productive part of the work the pupils are mainly thinking about the solutions to the problems, which they often do in small groups of 2-4. If possible each group is in a different room. At times they do individual work, which mostly means thinking about 'lightning round' questions (that is a plenary session at class 
when the students may answer questions with a short time limit), or at times problems that take a few minutes to solve.

As seen above, thinking as part of a group is assigned great importance. However, special rules apply here. Group work does not mean that once somebody solves a problem he or she shares the solution with the other group members. The objective is for as many pupils as possible to find a solution through his or her own efforts as much as possible. To facilitate this objective, the rules of team thinking are as follows: 1) If possible, everybody should think about all the tasks independently. 2) If there are some pupils who have problems with the same task, then collective thinking begins. It is only then that group brainstorming can start and alternative solutions can be proposed, which then can be solved together with group effort. 3) If a pupil has solved a problem, he or she can neither share it with the other members, nor help them. (In the week-end camps there is a period, called Period of Team Competition, when pupils are exempt from rule 3). [Note - there is a potential link here with Libby Jared's chapter]

If work is done in one classroom, it is bound to be apparent when someone has solved a problem, which can reduce the enthusiasm of most of the pupils. Moreover, if several pupils have already solved the same problem, it will expressly intimidate those who have not succeeded in doing the same. Such situations can be avoided much more readily if the groups work in separate rooms, and there is the added benefit of solving the problem of differentiated instruction.

A great role is played in Pósa's lessons by pupils learning how to ask questions. Pupils are often asked what they would want to ask in a given moment, i.e. what they are curious to find out more about based on what they have just heard. It is of crucial importance as it helps pupils to understand that what they are working on is interesting and exciting, and it will even be more so if the process is guided by their questions. A significantly more challenging task is to teach pupils to ask 'good' questions. Of course the notion of 'good' is highly subjective. As years go by, pupils gradually realise that a good question is valuable; it is added to the list of problems to be solved, often with the name of the person who asked that particular question. As a result, pupils are increasingly able to ask unusual and creative questions that might lead to exciting solutions.

Another highly important principle in Pósa's approach is the freedom to make mistakes. It often happens in schools that pupils who do not know something, think something wrongly or 
have an incorrect solution are put to shame and find themselves in an unpleasant situation. This never happens in Pósa's workshops. Since pupils are socialised in the school, it requires great effort on their part at first to stick to their opinions and solutions even if they are not completely sure about them being correct. The pupils must be aware that everybody can make mistakes during the process of discovery, and that there is no shame in that.

Pósa and his disciples regard their students as colleagues, and, if possible, as friends and equal partners. Unlike in the traditional hierarchical teacher-pupil relationship, in their approach and method pupils are on a far more equal footing than conventionally is the case. They also follow the development of their pupils in areas of their lives other than mathematics, and, if necessary, they help them well beyond nurturing their mathematical talent. It is, therefore, often the case that a real, meaningful human relationship is formed with the children that continues even after their studies in gifted camps come to an end.

\section{Principles of nurturing mathematical talent}

It follows from Lajos Pósa's way of thinking and system of values that in his basic teaching principles he does not distinguish between 'average' and mathematically gifted children, since he believes that the joy of independent thinking and creativity, the skill of asking questions and the right to make mistakes are equally important for all pupils.

The difference takes shape in the concrete tasks. It is also important for 'average' pupils to be given problems that are suitable for them but test their abilities and knowledge to the maximum degree. However, less gifted children find it more difficult to concentrate for extended periods, and they are quicker to regard it as a failure on their part if they are not able to solve a problem. These differences must also be considered when workshops are designed.

\section{The concept, history and practice of Pósa's weekend math camps for the gifted}

The history of Pósa's weekend camps for mathematically gifted children goes back to 1988 . Having seen many summer camps and others organised during the school terms, he thought it might be worthwhile to launch a camp for 15-20 clever seven-graders where they could work on mathematical problems together in a concentrated way. Before the camp started he had trained 
most of these pupils on an individual basis, which meant 3-4 hours of doing maths under his guidance.

Pósa's math camps were always, and still are, completely independent from main stream education. The typically 45-minute mathematics lessons in schools basically do not provide the opportunity for in-depth, extended periods of thinking. Gifted children attend various schools, and they are normally bored in the mathematics lessons; they might even be considered 'weirdos' and in the worst case scenario they are excluded from the social network of their class. It is important to note that when these children are together for a longer period of time, doing something that they especially love - and, on top of this, not only are they not thought of as strange but as absolutely normal - they find themselves in a much calmer psychological environment, which can further enhance their performance. Hence, the primary reason why camps became the chosen form of gifted education in Pósa's work was because the children felt extremely happy in such an environment.

The group of pupils that participated in Pósa's first gifted camp worked together for six years. Of course there were slight changes in the composition of the group, as some left and some joined later on. This trend has not changed ever since. A standard group, typically comprising 2035 pupils, is formed from seventh-graders, who then work together until the end of the eleventh grade. The venue is usually the dormitory building of a primary school in Budapest, where there are many small rooms allowing small groups to work and think together under pleasant circumstances.

In the first twenty years Pósa's camps did not have a unified and consistently applied pattern, but since 2008, when others also started running camps following Pósa's method, an utterly reliable and solid system has developed. (Pósa is present in most of these camps, and the camp leaders regularly ask him for his professional opinion.) Within the framework of this system a camp group now has 2 or 3 weekend events a year. The first group had 7 or 8 weekend camps every year, and the material they worked on was considerably more expansive than these days, so it partly functioned as a math circle.

At present work is conducted in nine parallel groups, so usually one group has two or three weekend camps, and, accordingly, the professional material has also been restructured. Initially 
camps were not organised separately for the different groups each year, as this practice was only established by the late 1990s. Since 2008, however, two camp groups are started almost every year. The first one comprises the mathematically most gifted pupils of the given year in Hungary, while the second one is organised for talented, curious and ambitious but not necessarily exceptionally gifted children. The selection of the pupils for these two groups is preceded by a long preparatory process. For example, in some cases the parents themselves indicate well in advance that they would want their children to participate in the camp. At first Pósa and his colleagues do not know much about the children, and they are put into one or the other of the two groups based on this limited information and the competition results. Then, during the first three or four camps they gain a better understanding of the pupils: they can see their thinking processes better, and they learn more about their talent.

The composition of the two groups is always modified using the above-mentioned information, and changes are made solely with the permission and support of the affected parties. During the first two or three camps it typically turns out that there are some children who do not perform well in competitions because of anxiety or perhaps they are not fast enough, but once they find themselves in a peaceful, friendly and non-competitive environment their performance is vastly enhanced and they come up with brilliant solutions. Moving from one camp group to the other is not only dependent on mathematical talent and performance. Great emphasis is placed on how pupils can fit in socially. The boundaries between the two groups are never sharp, and decisions are never bureaucratic but rather carried out with the interests of the particular child or children in mind.

Pupils can start attending weekend camps in seventh grade (age 12-13). The teachers get to know most of them during a summer math camp, which is organised by Pósa-students and led by the second author of this chapter, and select them based on their experiences. Participation in summer camps is based on results achieved in nationwide competitions. For some time a principle was followed, in which children were invited to the summer camp if they were ranked in the first few places in what were regarded by the organisers as high standard competitions. Later the invitation system was changed because there are pupils who are always ranked between $6^{\text {th }}$ and $10^{\text {th }}$ place in these competitions and they were previously not invited but it is obvious that they were among the top 15-20 most gifted children in their age group. As a result, the selection 
method was changed and a rather complicated procedure was introduced: the competition ranking no longer plays a role, only the score achieved, and its deviation from the average score of the pupils ranked in the top 30 in the nationwide competition of the given year. The different competitions are weighted: those testing logical reasoning are given more emphasis, while less is attributed to those based on multiple choice questions. A minimal score is counted for group competitions, as in these it is often the case that the whole group's success is determined by one pupil's contribution.

Unfortunately, the proportion of girls in the top achievers in mathematics has been traditionally very small. If the above calculation is taken strictly, only about one fifth of those at the top are girls. When it comes to inviting participants to the camps, the organisers increase this proportion to a quarter by applying positive discrimination in the case of girls. On average the same proportion applies to the weekend camps too, but significant deviation can also occur. (There is a group with only four girls out of the total number of 35, but in another one 12 pupils out of the total 30 are girls.)

Participation in the weekend camps is not only possible through the summer mathematics camps. Many teachers all over Hungary know about Pósa's gifted camps, so he gets a lot of recommendations as to who could be potential participants. At other times parents seek out Pósa asking him to assess their child, and if he sees talent there he should involve him or her in the work of the given camp group. Also, some schools contribute several pupils to our camp groups every year. Pósa or his colleagues usually pay a visit to these schools, hold a three to four-hour workshop for the children and invite some of them to participate in the camp based on their performance.

All in all, children can get into the camps through various channels, as no central talent screening programme operates in Hungary and Pósa does not have the means to screen talent in a comprehensive way. Since teachers and even parents can recommend children for participation in these camps, doubts might arise in regard to the objectivity of the selection process. However, Pósa and the other camp leaders hold preliminary sessions of 2 to 3 hours in duration for the overwhelming majority of the children recommended by teachers and parents with the aim of establishing whether the given children are suitable candidates for the camp. Moreover, every child has to answer a set of questions before joining the maths camp. These are not especially 
difficult questions but are rather designed to test if the applicants have the ability to work hard and reliably in the long term. It is important to not admit children who are less gifted since they might be in for a great disappointment. There is a huge gap between a pupil who is in the top 20 in Hungary and another who 'only' has an excellent grade in mathematics in his or her school. Of course the latter child is also very good at maths but a potential disappointment in the camp might negatively affect his or her future approach and performance to learning.

It frequently is the case that a pupil joins a camp after grade seven. It is well known that some gifted children mature more slowly, and their exceptional talent does not yet manifest when they are seventh-graders. Therefore, if it is discovered by ninth grade that a child is gifted, he or she will be invited to the camp. If the invitation is accepted, the 'late comer' child is given thorough preparation from the material of previous camps to catch up with the others. This is of crucial importance since Pósa's camps are constituent elements of a long process and not separate units independent of each other. Thus, a new member must be familiar with all that had gone on in previous camps and understand the processes and ideas that had developed there.

Pósa began to develop the material used in the camps in 1988. At the time he only planned ahead for two to three weekend camps; then he did not yet have the systematically structured gifted education material to be used over five years that is available today. In fact, the material that is used nowadays consists of far more that can be fitted into five years according to the current structure of the camp programme. It is the composition of the given camp group, their strengths and interests that determine which parts of this extensive material will actually be used.

The maths curriculum of the Pósa camps places emphasis on gaining more in-depth understanding of the concepts and ways of thinking learnt in the school, as well as on creative, inquisitive and persistent thinking. New definitions and theorems rarely form part in these camps. Instead, different processes develop simultaneously, i.e. distinct ideas and sets of problems might converge at a given moment. To borrow Pósa's own metaphor, a camp is like a symphonic orchestra with many parts that must be played together. When one part is played louder, the others become quieter to allow it to be heard. But the piece will be complete if all the parts can be heard in unison. He said he is always moved by those moments when seemingly distant areas meet unexpectedly, and the pupils can personally experience that in mathematics everything is connected with everything else. 
The material used in the camp has been continuously developed since 1988, and is adapted to suit the given group. Many of the questions asked by the children have been integrated into the exercises used in the camps, and Pósa teachers often share the congenial solutions provided by the camp participants instead of their own, less inventive solutions. The gifted camp curriculum is also adapted to the school curriculum: certain areas, which are effectively taught within the framework of Hungarian spec. math. instruction in schools, are completely left out, while others are assigned special importance in the camp since in-school gifted programmes cannot focus on them so successfully. Children who participate in the camps come from schools from all over the country, and the curricula might have significant differences. Therefore, the possible gaps resulting from the discrepancies between previously acquired sets of knowledge must be bridged. Fortunately, the problems addressed in the camps rarely require factual knowledge and are far more reliant on creative thinking, with understanding the essence of things being placed at the focus of attention.

The teaching in Pósa gifted camps encourages learning through discovery, which basically means that the pupils have to solve mathematical problems without previously being taught specific methods, theorems or definitions for their solutions. They are expected to solve the problems independently, without being previously spoon-fed knowledge. However, careful preparations are made before problems are presented to the children: the teachers try to ask questions that require serious effort on the pupils' part but are still feasible to be answered at their level. Teachers make absolutely sure that the task they give to the pupils is thoroughly prepared and the most important ideas are available for its solution. It is of the utmost importance that the problems are exciting and inspiring. The backbone of mathematical problems presented in the camps is formed by so-called threads (series of problems) that typically span long periods of time, often several years. It is a rare exception that a task is built on a single idea that will only be used once. The aforementioned threads are not only made up of the conventional areas of mathematics (e.g.. algebra, geometry) but rather fundamentally important ideas and less obvious connections. The solution to these problems predominantly requires a way of thinking that can be successfully applied to fields otherwise distant from one another. (For example, pupils are given a series of increasingly difficult tasks the solutions to which are determined by starting out from an extreme position and proving the desired statement from there.) 
For the majority of the time they spend in the camp pupils work in small groups of two to four, as earlier mentioned. They are not in a classroom but in separate rooms of a large building where they can find the position most comfortable for them: some sit on chairs, some lie on beds and some others might ponder the solutions to problems lying on the carpet.

A regular part of every camp is what we call Saturday Afternoon Team Competition, when each team is given five problems to solve in about three hours, thus creating a bit of a competitive atmosphere. The problems typically asked of them are like these: identify the heavier weight by the minimum possible weighings; chose as many numbers as possible from a set based on a given condition; build a given structure using as few blocks as possible. When the competition is evaluated some of the teams will be in the 'performed very well' category, while a somewhat smaller proportion will be in the 'performed even better' category. All the teams get chocolate as a reward, but those in the second category will get a little bit more. Hence, it can be seen that in Pósa's camps that the edge is taken off competitions to the maximum possible degree. At this point readers might ask the logical question why are there not more competitions in the camps once the children are selected based on their competition results, and this is how they often attract the attention of camp leaders. The answer is that for Pósa and his students mathematics is not seen as a competition in the least bit. The reason why they use competition results in the screening process is simply that there is not a more efficient selection method available at the moment. Yet, competition has no place in real mathematics. Problems do not need to be solved within a given deadline. Problems posed by mathematics research are not carefully prepared and difficult but it is still possible to solve them. No points are given for exciting, forward-pointing questions at competitions, but Pál Erdős's example proves to us all how valuable a good question can be in mathematics. He posed many questions which vivified different areas of mathematics. (Richard K. Guy wrote in his book Unsolved Problems in Number Theory: "This book is dedicated to Paul Erdos, who not only possessed the art of asking the right question, but of asking it of the right person.”)

'Evening guests', who are not experts in the field of mathematics but broaden the way of thinking of these exceptionally talented children with interactive programmes, are frequently invited to the weekend camps. 
Besides Pósa there are five of his former students who run gifted camps. Their work is assisted by four to seven helpers every time who are almost all university students, and former gifted campers themselves, working on a voluntary basis. This system developed gradually, since at first Pósa ran camps on his own, and then with the help of one or two people. Now the helpers play an important part as they monitor the work done in small groups, and they are also actively involved in organising the free-time programmes, i.e. they form an integral part of the system. In this way the next generation of camp leaders is also ensured since the helpers first gained personal experience in the camps as members and then, as adults, they can participate in the work and take an active part in it, observing things from a teacher's viewpoint. Later they can also integrate Pósa's methods into their own teaching, and, if they want, they can eventually become camp leaders.

The weekend camps are free of charge, and the costs are covered by A Gondolkodás Öröme Alapitvány (The Joy of Thinking Foundation). The foundation may ask more well-to-do parents for a contribution but no gifted children are ever left out of the camps for financial reasons.

The weekend camp groups and the MaMuT (literally: camp for mathematical amusements) groups are full of pupils who are International Mathematical Olympiad, Middle European Mathematical Olympiad, European Girls' Mathematical Olympiad medallists and several of them are International Physics Olympiad and International Olympiad in Informatics medallists. Nevertheless, Pósa and his students never evaluate the children's work based on their results achieved in Olympiads and other competitions; they are happy to see their pupils' success at competitions but what means far more for them is that the children enjoy their time in their camps and gain life-long experiences and build friendships.

\section{The role of experiential learning in the work of gifted educators}

Since the development of gifted pupils follows a different course than that of the average learner, these children require an individually designed pedagogy. Thus, one of the specialties in the work of gifted educators is that they need to rely on experiential understanding, which facilitates the understanding of individual pedagogical cases, to a greater extent than their colleagues teaching pupils within the average ability and performance range in mainstream education. 
Although ELT (Experiential Learning Theory), which was one of the most important developments in the history of 20th-century pedagogical thought (Kolb \& Kolb, 2008), primarily examined the learning processes of managers through their work experience and built up a theoretical framework based on these findings, the main creators of the theory were well aware that experiential learning is continuously present and active in every segment of our lives, hence just as much within the framework of formal education as in our everyday activities, for example. One of the important characteristics of ELT is its focus on the mutually supportive dual processes of activity-reflection and experience-abstraction (Kolb \& Kolb, 2008), implying two crucial questions regarding learning processes conducted in a holistic environment: in what role is somebody able to reflect upon the activities of their pupils/trainees and their own activity, and in what way and how efficiently can this person abstract at a pedagogical level his or her experience gained from the activities? Understanding this is of course an exciting challenge faced by teachers who were given formal training, regularly participate in further training and work in formal education, but it is even more compelling a challenge to understand the professional developmental processes of those individuals who pursue a pedagogical activity but were not given formal teacher training and work outside the framework of formal education.

In other words, the former group of teachers can base their professional development on a formally received system of pedagogical knowledge - which of course is built on the layman's/naïve pedagogical theories of the field's experts but is integrated with formal systems of knowledge, and with the dominance of these in many of their elements - while the individuals in the latter group are left to rely only on layman's/naive pedagogical theories and they themselves need to derive and develop a pedagogical system of understanding that is at least as much or even more efficient than the formal system of knowledge. Thus, compared with formally trained pedagogues, it is by far more critical for non-formally trained educators that they can successfully operate the system of two dual feedbacks of experiential learning (activityreflection, experience-abstraction) since they can only exploit this system during their work and the continuous development of their activity.

Lajos Pósa belonged to the group of non-formally trained pedagogues. He was fortunate to have had family circumstances that significantly helped him in the first steps of his professional development. Of primary importance was his mother's influence as she was an 
outstanding figure of nationwide recognition in the field of knowledge which occupied a place in the intersection of mathematics and its professional instruction. Pósa lost his mother early but up to her death she had devoted much time and attention to his mathematical development. Thus, Pósa - who was extremely advanced for his age and exceptionally gifted intellectually, not least and in the field of mathematics - had the opportunity to gather and reflect upon experiences in the area of teaching mathematics that were coupled with positive emotions, thanks to his mother. There were probably no others with his kind of disposition in Hungary at the time who were given such an opportunity.

After such beginnings, and again being fortunate, he became one of the pupils in the country's first special math class for gifted children. Here he was surrounded by peers - similar to him and later internationally recognised for their achievements - who created a mathematically and intellectually stimulating environment, had a maths teacher who was able to work using nonconventional methods and, thanks to his form master, he also had the chance to see a pedagogical pattern in operation that served as life-long inspiration for him. At the same time, it is important that during these years, and even beforehand, he was the beneficiary of another, unique activity of nurturing mathematical talent: this model was provided to him by Pál Erdős, who developed Pósa on an individual basis, conducting the kind of gifted pedagogy activity in which the pupil was treated as a colleague, as attested to by their joint publications they co-authored from Pósa when he was only 13 years of age.

In addition to several other possible influences, what Pósa definitely learnt from the individual development work he received from his mother and Erdős is that a major role can be played in the development of mathematically gifted children by forms of instruction taking place outside the framework of formal education, not fully separate from it but rather complementing it. When in his freshman year, as a young adult, Pósa began to work with mathematically exceptionally gifted pupils in his former secondary school, such as László Babai and others, he chose the workshop as a form of instruction, marking out the path he later followed. It is important to note that his early gifted education attempts were a positive experience for him, which obviously contributed to the fact that he has continued this activity besides his work as a mathematician and researcher as well as a professor in higher education. 
The next and perhaps most crucial development in Pósa's gifted education activity was when he realised that gifted camps - which represented a form of gifted pedagogy work that was not unknown either in Hungary or other parts of the world at the time - can be adapted to his own gifted educational concepts and used successfully in the development of mathematically gifted children. When he arrived at this conclusion and reached a point where he was able to implement his ideas he had already built up a mature enough theory as well as extensive feedback, allowing him to see that his gifted education ideas can be efficiently put into practice. An important aspect of Pósa's personalised system of teaching mathematics and nurturing mathematically talented children - which was fundamentally developed by him but was further improved and enriched upon the inspiration of outstanding professionals in the field - included teaching pupils at their own pace and level, teaching them through discovery and through the joy of thinking, exploiting the benefits of self-improvement and mutual inspiration inherent in competition, as well as the fact that in many cases, or at certain points in the process, mathematical development is more efficient if it takes place in a social learning environment. In the next decades Pósa further developed these and other pedagogical axioms of his, always taking into consideration the practical experience acquired in the field of gifted education and abstracting it in a process of continuous professional self-development.

Another systematically crucial element in Pósa's work has been the passing down of his method, i.e. its dissemination in time and place. Generally speaking, self-made gifted education coaches like Pósa himself are often on their own, in the sense that their individually developed pedagogy and its practice are only applicable to them; in other words, once they stop their activity, the thus far successful method 'disappears' and no longer makes an impact on the profession. Gifted camps for mathematically talented children as a form of gifted education (supplemented by individual activities and development) provided an excellent opportunity for Pósa to 'bring up' the next generation of young maths teachers and gifted educators as they had the chance to personally experience the strengths of his gifted education method, and of course also those elements that required revision and further improvement. Since Pósa systematically invited these secondary school pupils and university students as assistant teachers in his gifted education camps again and again, they had hands-on experience of working with school-age children, while also being able to perfect their own, at that point lesser developed and predominantly layman's pedagogical views and ideas through collaborating with Pósa, from 
whom they could learn numerous gifted education methods and patterns. Hence, Pósa established his own school of gifted education in Hungary in the area of teaching mathematics, confirming in an exemplary fashion that one of the key attributes of genuinely efficient gifted education methods is that they become an organic element in the pedagogical development of a given educational environment, thus exerting a long-term influence lasting for generations. The gifted education context and genealogy manifest in Pósa's life and activity can serve as an instructive and exemplary model for gifted pedagogy professionals. The more than a 100-year-old tradition of Hungarian gifted education, which became manifest for example in $\mathrm{KöMaL}^{2}$ and the system of nationwide math competitions; Pósa's mother's work; Erdős Pál; Pósa's math teacher and his homeroom teacher in the secondary school; Pósa himself and his students, including the second author of this study, as previously mentioned who are now already active participants and shapers of Hungary's gifted education in mathematics - all these people and all these things create a chain, a system which organically expands in space and time. Several of Pósa's peers - unlike Pósa himself - also work in formal education but their main focus is on gifted camps for mathematically talented children, their individual development and other forms of gifted education activities, all aimed at raising new generations of great mathematicians and gifted education coaches in mathematics.

\section{[c.8800 words inc. refs]}

\section{References}

Borovik, A. (2012). Free math schools: Some international parallels. The De Morgan Journal, 2 (2). 23-35.

Czeizel, E. \& Batta, A. (eds.) (1992). A zenei tehetség gyökerei. [The roots of musical talent]. Budapest: Arktisz.

${ }^{2}$ Launched in 1894, KöMaL is a journal of mathematics (now also physics and IT) for secondary school pupils, announcing correspondance competitions in many categories. Children are given one month to answer the questions of a given series of problems, expected to provide precise and detailed solutions to the generally challenging tasks. For example, one of the conditions of qualifying for the Hungarian IMO team is participation in the mathematical KöMaL point-based competition, as it significantly helps pupils to learn how to explain their solutions efficiently, clearly and accurately. 
Fried, K. (2010). Case of Hungary. In A. Karp \& B.R. Vogeli (eds.), Russian mathematics education: History and world significance (pp. 338.346). Singapore: World Scientific Publishing.

Furnham, A. F. (1988): Lay Theories: Everyday Understanding of Problems in the Social Sciences. Pergamon, Oxford. 189-207

Huszár, K. (2011). Creating a culture of problem solving: The Hungarian approach to education. Budapest: Eötvös Loránd University.

Lave, E., \& Wenger, J. (1991). Situated learning: legitimate peripheral participation. Cambridge: Cambridge University Press. http://dx.doi.org/10.1017/cbo9780511815355.003

Pósa, L. (2013). Pósa Lajos: CV. Unpublished manuscript.

Stockton, J.C. (2010). Education of mathematically talented students in Hungary. Journal of Mathematics Education at Teacher College, 1, 1-6.

Szabó, O. \& Orosz, Gy. (2012). Rábai Imre tanár úrral készült interjú. [An interview with Imre Rábai]. http://matekold.fazekas.hu/portal/rolunk/c/page/rabai_imre.html Downloaded: 27. 09.2015

Szegal, B. (1989). A tehetséges gyermekek a Szovjetunióban: Elméletek, felfogások, álláspontok, kutatás és gyakorlat. [Gifted children in the Soviet Union: Theories, views, standpoints, research and practice]. In Ranschburg J. (Ed.) Tehetséggondozás az iskolában [Gifted education in the schools], (pp. 247-282). Budapest: Tankönyvkiadó.

Vogeli, B.R. (1968). Soviet secondary schools for the mathematically talented. Washington: National Council of Teachers of Mathematics.

Zucker, D.M. (2009). Teaching research methods in the humanities and social sciences: How to do case study research. In M. Gardner, B. Kawulich \& C. Wagner (Eds.), Teaching research methods in the humanities and social sciences (171-182). Surry: Ashgate Publishing. 